\title{
Autonomía de los aparatos-miradas sin imágenes. Leyendo a Flusser en la era postmediática
}

Victor Silva Echeto ${ }^{1}$

UPLA e ARCIS

1. Doutor em estudos culturais: literatura e comunicação, professor e investigador da UPLA (Universidad de Playa Ancha de Chile) e professor da ARCIS (Escuela Latinoamericana de Postgrados de la Universidad de Artes y Ciencias Sociales). 


\section{Resumo}

Flusser percebeu que as relações entre tecnologia, comunicação e cultura devem ser analisadas em seus altos níveis de complexidade. Ele não foi um cúmplice de "funcionários" que desenvolvem "programas", mas também não concordou com "falsos" críticos, que são incapazes de entender as mudanças trazidas pela digitalização. Sua filosofia é criativa, intrigante, mas também ambígua e contraditória. É uma filosofia de estranheza, de "migração" e conceitos.

\section{Palavras-chave}

Flusser, aparelhos, imagens, pós-mediática

\section{Abstract}

Flusser realized that the relationship between technology, communication and culture should be analyzed in their high levels of complexity. He was not an accomplice to "employees" that develop "programs", but he did not agree either with the "false" critics who are unable to understand the changes brought by digitization. His philosophy is creative, intriguing, but, at the same time, ambiguous and contradictory. It is a philosophy of strangeness, of "migration" of concepts.

\section{Key-words}

Flusser, appliances, pictures, post-media 
La revolución informática le dio la posibilidad de fabricar objetos que portaran la información elaborada de manera débilmente adherida y que permitieran, por tanto, transmitirla de objeto a objeto. Su resultado son los "objetos postindustriales". (...) Hoy por hoy, ya es técnicamente (y teóricamente) posible fabricar, transmitir $y$ almacenar informaciones puras, no aplicadas sobre objetos (...). El ser humano dejará de ser "objetivo" (frente a objetos) para volverse intersubjetivo (para otros). (Vilém Flusser)

Las relaciones entre fantasma e imagen están planteadas desde el inicio. Tal como la sombra del rey Hamlet, el efecto de visera (ver sin ser vistos) es una de las características más destacables de la imagen en la era postmediática (Sodré, 1996). Así, el entorno "se está volviendo cada vez más blando, más nebuloso, más fantasmal, y el que quiera orientarse en él tiene que partir de ese carácter espectral que le es propio" (Flusser, 2002, p. 105).

Vilém Flusser (2001; 2002; 2004; 2005; 2008), en diversos escritos, considera que la imagen en la época posthistórica transforma la era postindustrial en "información pura" (Flusser, 2001 160). La imagen "muestra a modo de ejemplo la transición de la sociedad postindustrial a la sociedad de la información pura”. Así, “enseña de manera ejemplar las perspectivas (en parte fantásticas) que esta transición ofrece, así como los problemas sin resolver (en parte, quizá, imposibles de resolver) que encierra" (Flusser, 2001, p. 160). Para Vilém Flusser, en ese contexto teóricopráctico, la fotografía "es uno de los fenómenos más fascinantes 
del presente y del futuro inmediato". Y este es uno de los aspectos más destacables de su propuesta teórica, ya que considera que "no lo es como fotografía solamente, sino también, y sobretodo, como modelo" (Flusser, 2001, p. 160). Esos modelos dejan de ser representativos, y se transforman en cartografías, hologramas, copias de copias, como en el diseño posthistórico; son "formas" que rellenan transitoriamente la materia (Flusser, 2002, p. 30); son in-formaciones, imágenes de síntesis. De esa forma, se complica la relación entre forma y materia. En resumen, ya en la fotografía y, posteriormente, en el cine, en la televisión, en los hologramas, en la informática, en definitiva, en la digitalización, se vuelven cada vez más complejos esos modelos-(des)modelados.

Así las cosas, el ser humano deja de ser objetivo y subjetivo. Ese humano es un ser antinatural y, por tanto, artificial, ya que produce comunicación y cultura, transformándose en "intersubjetivo", un sujeto-para-otros. "A comunicação humana é um processo artificial. Baseia-se em artifícios, descobertas, ferramentas e instrumentos, a saber, em símbolos organizados em códigos" (Flusser, 2007, p. 89). ${ }^{2}$ El mundo codificado transforma ${ }^{3}$ a la comunicación y a los sujetos, ya que éstos son testigos y víctimas, pero, paradójicamente, no siempre son conscientes de los cambios que se están viviendo en su entorno cultural. ${ }^{4}$ Es así que Flusser, en diversos escritos, se dedicó a demostrar la hipótesis de que el significado general del mundo de la vida cambió, se transformó, mutó, producto del impacto de la revolución en/de la comunicación.

\section{Filosofía, imágenes, visualidad}

Si la filosofía "crea conceptos", esa creación debe ser singular, específica y, por tanto, no universal. Flusser, durante su trayectoria intelectual, fue un despiadado creador de conceptos singulares. Paralelamente, diseñó y proyectó una filosofía de la comunicación y de la información, con los propios conceptos de estas áreas de conocimientos. $\mathrm{Si}$, en muchas oportunidades, la filosofía no está necesariamente en los filósofos profesionales (los funcionarios de la filosofía les llamaría Flusser), sino en el afuera descampado y desprotegido, el teórico nómada de países y culturas construyó una poderoso filosofía de la comunicación y una epistemología critica,
2. Pieza original de la traducción en portugués.

3. Flusser le llamará en algunos momentos "revolución en las comunicaciones" y, en otros, "sociedad de la información”. Véase la actualidad que adquiere su análisis y la urgencia de tomarlas como una de las bases de la epistemología de la comunicación.

4. "Na verdade, temos consciência dos efeitos, por exemplo, da televisão, das propagandas ou do cinema" (Flusser, 2007, p. 127). Pieza original de la traducción en portugués. 
5. Su debate con Kant es implícito y explícito a lo largo de su obra.

"Somos los auténticos maestros hechiceros, los genuinos diseñadores, y eso nos permite, ahora que ya le hemos ganado la mano a Dios, hacer oídos sordos a todo canto de sirena y a todo Immanuel Kant que proclame con voz melodiosa la cuestión de la realidad" (Flusser, 2002, p. 45). Pero

hay otros debates con la filosofía kantiana así como con el funcionalismo (fue uno de sus mayores críticos): “Entre el bien puro (el 'categórico'), que no es bueno para nada, y el bien aplicado ('funcional'), en el fondo no puede haber compromiso ninguno, porque, en último término, todo aquello para lo que es bueno el bien aplicado es, categóricamente, malo"

(Flusser, 2002, p. 40). no complaciente, alejada de los "cantos de sirenas" tecnocráticos. Pero, no por ello, le dio la espalda a las transformaciones técnicas, como lo han hecho algunos miopes teóricos que se amparan en negar esos cambios y mutaciones. Flusser entró en el debate sobre las "imágenes técnicas" (2008), sobre la pantalla (tela) y puso en cuestionamiento la trascendencia desde el elogio de la superficialidad. "A imagem técnica ou tecnoimagen é a imagem pós-escrita, não mais feita de planos ou superfícies, mas de pontos, grânulos, pixels", escribe Norval Baitello Jr. (2008, p. 10) en el prefacio a la última obra de Flusser editada en portugués.

Es así que nos encontramos en su filosofía con las nociones de información, cibernética, canal, técnica, entropía, neguentropía, diseño, fractales, hologramas, programas, pantalla (tela). Si sumamos la "filosofía de la fotografía" (filosofia da caixa preta), la filosofía del diseño y, yo agregaría, la filosofía del canal y la filosofía de la pantalla (filosofia da tela), nos encontramos con una abundante epistemología de la comunicación y, además, una poderosa filosofía de la comunicación. La segunda ley de la termodinámica, las "no cosas", los cambios espaciales que ponen en cuestionamiento los apriorísticos kantianos ${ }^{5}$ de tiempo y espacio, entre ellos, la tridimensionalidad desestabilizada por la nulodimensionalidad (o dimensión cero), los cambios en la codificación y la nueva imaginación son algunos de los conceptos que atraviesan parte de su extensa obra y que adquieren actualidad para pensar la comunicación, desde una ontología de lo singular y del presente.

La transición de la cultura del texto a la cultura de la imagen está acompañada del pasaje de la sociedad industrial a la postindustrial, de la historia a la posthistoria, de la materia a la postmateria, de la letra al número, de lo analógico a lo digital. Es decir, de la cultura lineal de la historia (centrada en la escritura) a la nulodimensionalidad y la circularidad de la magia posthistórica. Del trabajo al juego, un juego macabro: "El nuevo ser humano ha dejado de ser un actuante, para convertirse en un jugador: un homo ludens, ya no un homo faber. Su vida ya no es un drama, sino un espectáculo. No tiene argumento, no tiene acción, sino que consiste en sensaciones" (Flusser, 2002, p. 107). Sin embargo, no todo su planteamiento es tan optimista, porque, así como hay juegos y jugadores, hay marionetas, hay un "totalitarismo programado", pero que se vive con la satisfacción del éxtasis. Un totalitarismo que 
pasará inadvertido y formará parte del nuevo mundo feliz. Como la Guerra, juego macabro si los hay: "supongamos que en lugar del cortapapeles hubiéramos escogido uno de esos misiles que fueron introducidos en la Guerra de Irak. No cabe duda de que los diseñadores de esos objetos son seres humanos de una extraordinaria nobleza: los misiles son elegantes y pueden ser considerados como las obras de arte características de hoy en día”. No hay duda, tampoco, "de que son gente extremadamente servicial: si bien los misiles son sistemas complejos, son tan agradables que incluso unos semianalfabetos imberbes de la cuenca alta del Éufrates pueden utilizarlos". En definitiva: "se puede ser de la opinión que los diseñadores de los misiles son demasiado buenos tipos, pues dichos objetos no sólo matan bien (...), sino que también provocan el lanzamiento de otros misiles, que terminan matando a los usuarios de los primeros" (Flusser, 2002, p. 38). De ahí la crítica a la frase de Goethe de que el ser humano debe ser "noble, generoso y bueno". La humanidad se alejó cada vez más de la ilustración e ingresó por la puerta de atrás a la Edad Media.

\section{Imágenes, visualidad, postmagia}

Si la mirada mágica es la primera edad de la imagen, y el arte, transformado en estética, la segunda, en la edad visual se retorna a la magia posthistórica. Genealógicamente las ideas de Flusser van y vienen, son como hologramas y fractales. A diferencia de muchas teorías sobre la escritura que consideran que desde la primera oralidad-mágica se pasó a la escritura-lineal ${ }^{6}$, donde Occidente se convirtió en el reducto donde nace, se desarrolla y consolida la historia, Flusser fractura esas posiciones lineales, evolucionistas y plantea la idea de quiebre, "catástrofes" y "crisis" de esos estadios en los que se produjeron diversas mutaciones culturales. No venimos, pacífica y evolutivamente, de una oralidad "prehistórica" primigenia y, pasando por la escritura de la historia, nos conducimos a la tecnocéntrica posthistoria digital, en una línea ascendente que nos conduce al progreso, sino que hemos atravesado tres catástrofes y mutaciones. Hoy, nos encontramos en la tercera de esas catástrofes.

Como indica con acierto Rainer Guldin, Flusser cuestiona:
6. "Etnocéntrica, logocéntrica”, en términos de Jacques Derrida (1971). 
7. Pieza original de la traducción en portugués.

8. "Las imágenes son superficies con significado" (2001, p. 11).

9. "Los textos son líneas lógicas de conceptos enhebrados a modo de ábaco" (Flusser, 2001, p. 105).
A precedência temporal e a primazia consequente da palavra falada sobre a palavra escrita, desenvolvendo, a partir dessa ideia, uma redefinição radical do conceito da escrita, que envolve um criticismo da idéia de história progressiva linear e o inevitável etnocentrismo ligado a ela (Guldin, 2008).7

El ser humano, en términos de Flusser, "desarrolla en cada escalón una capacidad específica que le permiten fabricar sus medios". En otros términos: "en el ser humano surgen de forma escalonada nuevos niveles de conciencia que le permiten desalienarse". A esos niveles de conciencia emergentes les llama "poder de acción", "poder de representación”, "poder de concepción” y "poder de imaginación” (Flusser, 2001, p. 108). La especie humana "dispone del poder de acción”, que le permite fabricar instrumentos. Los homo sapiens disponen del poder de representación, que le permite fabricar imágenes. ${ }^{8}$ El sujeto histórico dispone del poder de concepción, que le permite crear textos. " "Y nosotros empezamos a disponer del poder de imaginación que nos permite fabricar imágenes" técnicas. Según el planteamiento de Vilém Flusser: "no ha existido en el pasado ningún poder de imaginación" en el sentido planteado. "Las fotos, películas, vídeos y hologramas son productos de un nivel de conciencia que antes no era imaginable ni concebible" (Flusser, 2001, p. 108). En definitiva:

podemos vivir en otros mundos. Podemos vivir el presente de varias maneras distintas. E incluso la expresión "el presente" puede significar varias cosas. Lo que acabamos de decir es ciertamente terrorífico, incluso monstruoso, pero los nombres que se le asignan son de los más tranquilizadores: ciberespacio o espacio virtual (Flusser, 2002, p. 45).

\section{El poder de imaginación en la era digital}

La apariencia "engaña", es - como el arte - una mentira, forma parte de un mundo alternativo. La desconfianza que ella generaba a Platón, pero, también, a Plinio el Viejo y a Descartes, se instala en nuestro presente iconoclasta, que, por eso, la intenta recubrir de textos, discursos u otro tipo de mediación representativa (que 
nos intenta proteger de esas apariencias). Flusser, en otro debate implícito con Kant, desconfía de esa estrecha relación entre arte y estética. No obstante, cabe aclarar que la relación entre estética y arte tiene una corta historia, y Flusser es consciente de ello. La estética fue un modo de la razón colonizar las sensaciones. Para Baumgarten, "el conocimiento estético media entre las generalidades de la razón y las particularidades de los sentidos" (apud Eagleton, 2006, p. 67). Como indica Terry Eagleton: "la razón debe entonces encontrar algún medio para penetrar en el mundo de la percepción, pero al mismo tiempo, bajo ningún concepto debe poner en peligro su propio poder absoluto" (Eagleton, 2006, p. 67). Así, el libro de Baumgarten Aesthetica de 1750, intentará mantener ese delicado equilibrio. Pero, siglos después Flusser lo tensionará, y desequilibrará nuevamente las relaciones entre razón y sensación. "Los mundos alternativos, con su apariencia digital, llevan esa inquietud a su punto culmine" (Flusser, 2004, p. 352). Para Flusser, "cuando se reflexiona sobre la digitalización, resulta indispensable partir de comienzos de la Edad Moderna”. En ese momento, "se descubrió que, para lograr el dominio del mundo, para comprenderlo, no era cuestión simplemente de observarlo ni de describirlo, sino que había que calcularlo". Y, aunque "bien podía ser inimaginable e indescriptible, pero a cambio de ello era calculable. Las consecuencias de este descubrimiento recién se hicieron evidentes en la actualidad con los mundos alternativos" (Flusser, 2004, p. 352). La teoría, a partir de ese momento, "no era la observación pasiva de los ideales, sino el desarrollo progresivo de modelos, que debían ser sometidos a la praxis, es decir, a la observación y la experimentación”. De esa forma, se dio nacimiento a la ciencia moderna y a la técnica, a la revolución industrial y a la apariencia digital (Flusser, 2004, p. 353).

La idea de que el mundo está codificado en números, sorpresa renacentista, todavía hoy no la hemos superado. Y aquí hay uno de los aspectos más destacables del planteamiento de Flusser y una de las teorías que adquiere mayor actualidad, frente a la tradición de corte semiológico que dominó en gran parte de Occidente ${ }^{10}$, para Flusser: "los números no son discursivos" ${ }^{11}$ y por ello no corresponden dentro de una línea". Es, por lo tanto, la emergencia "de un 'código alfanumérico"” (2004, p. 354). Para Flusser, se piensa en números, "en formas, en colores, en tonos" y, cada vez menos, "en palabras".
10. "Etnocéntrica, logocéntrica", en términos de Jacques Derrida (1971).

11. No obstante, considero que hay una diferencia entre el segundo Flusser (el de su período europeo) y el primero, que investigó, escribió y publicó en Brasil y en sus primeros años en Europa. Este último más fenomenológico, centra sus estudios más que nada en una filosofía del lenguaje, una fenomenología del brasileño y, en ese sentido, no plantea esa diferencia tan radical entre lenguaje, discurso y técnica, como se observará en ese segundo Flusser. Sin embargo, en esos primeros textos se observan algunas claves conceptuales que posteriormente desarrollará el segundo Flusser. 
La regla de su pensamiento es "matemática, cromática, musical, y cada vez menos 'lógica”'. Este tipo de pensamiento es:

cada vez menos discursivo y cada vez más sintético, estructural. Tras el abandono del alfabeto los números no solamente dejaron 'atrás' el pensamiento histórico, sino que han desarrollado un concepto del tiempo completamente no histórico (como se expresa matemáticamente quizá en la segunda ley de la termodinámica) (Flusser, 2005, p. 104- 105).

El pensamiento "causal histórico es apartado como un pensamiento estadístico calculador". El pensamiento "elitista se ha emancipado de la estructura discursiva de nuestro lenguaje y conoce, vivencia y valora el mundo y a sí mismo no más como procesos, sino como computaciones, algo así como sinuosidades de campos de relación”. Y sostiene Flusser una hipótesis radical para su época: "la lectura de letras va ha ser considerada en el futuro como un síntoma de mentalidad atrasada como por ejemplo el pensamiento mítico en la Época Moderna” (Flusser, 2005, p. 105). Mundo cuantificable e indescriptible. Por ello, "los números deberían escapar del código alfanumérico y hacerse independientes”. Las letras y sus linealidades "inducen al mero parloteo sobre el mundo y deberían de ser dejadas de lado como algo no adecuado a éste". Y, ese pasaje ya está ocurriendo, "los números están emigrando del código alfanumérico a otros nuevos (por ejemplo, al código digital) y sirviendo para alimentar ordenadores" (Flusser, 2002, p. 73). Una temporalidad y espacialidad que se transforman en la cinta de Moebius, donde el exterior y el interior ya no se distinguen.

Para comprender esos mundos paralelos y alternativos, hay que tener en cuenta - y Flusser es consciente de ello y lo reitera en diversos escritos - que no todos han dado el salto que va desde lo lineal a lo cero-dimensional (2004, p. 356), produciéndose, en ese contexto, la generación de una elite que piensa en números, una elite que computa, que crea modelos, una nueva separación en la sociedad entre los no lineales y los lineales. Así se producen dos consecuencias en el plano teórico: "el pensamiento calculatorio ha penetrado cada vez más en lo profundo de los fenómenos. Los ha analizado (descompuesto), y de este modo los fenómenos han adoptado cada vez más la estructura del pensamiento calculatorio" 
(Flusser, 2004, p. 357). Por lo pronto, “ya no se habla más de esa 'cosa extensa' original, sino de enjambres de partículas estructuradas en campos”. No obstante, no es tan sencilla la situación, ya que el conocimiento numérico es problemático desde el punto de vista teórico. Hoy no se puede dividir - como en otras épocas - la teoría de la práctica, sino que ambas se encuentran entrelazadas. Es así que la matematización de la filosofía o la filosofización de la técnica "constituyen las verdaderas metas de nuestro pensamiento". Esa nueva elite es la de los "programadores", "tecnócratas", "operadores mediáticos" o "constructores de opinión”. Funcionarios, les llamará desde su temprana Da religiosidade: a literatura e o senso de realidade, publicado por primera vez en 1965: "Nesse novo tipo o centro é ocupado pelo aparelho, e o horizonte é constituído de funcionários que funcionam em função do aparelho. Reluto em designar o funcionário pelo termo 'homem', já que se trata de um novo tipo de ser que está surgindo" (Flusser, 2002b, p. 84).

\section{Aparatos, autonomía, miradas}

Con referencia a las técnicas: en la era del poder de representación, existían instrumentos que se hacen imaginativos en ese contexto representativo; en la era del poder de la concepción, se convierten en máquinas - mientras que el poder de la imaginación los transforma en aparatos. Las imágenes técnicas hoy se basan en partículas del campo electromagnético: "hay que inventar aparatos capaces" de potenciar el "poder de la imaginación” convergente con la época actual. "Estos aparatos deben estar construidos conforme a la estructura compuesta de puntos del universo". O sea, "tienen que reunir los elementos en forma de puntos según un programa de manera aleatoria”. De acuerdo a esta hipótesis: "los aparatos pueden hacer este trabajo automáticamente, esto es, sin intervención humana”. Esa hipótesis sobre la autonomía de los aparatos, que cruza por la filosofía de la fotografía, la apariencia digital, y otros escritos de Flusser, tiene respuestas diferentes en diversos momentos de la obra del teórico. Hay momentos del análisis donde se destaca esa autonomía de los aparatos, mientras que, en otros, se plantea la necesidad del "gesto" humano que esté detrás del aparato, "gesto" como manipulación, como artificio, como falsedad (Flusser, 1994). 


\section{Conclusiones}

En definitiva, la autonomía de los aparatos es un dato del diagnóstico, mientras que la mirada - desprendida de las imágenes - es el "gesto" que visibiliza los "mundos paralelos", los presentes desligados de las cadenas causales del tiempo.

Flusser comprendió que las relaciones entre comunicación, técnica y cultura no se pueden reducir y, por ello, deben de ser analizados en sus altos niveles de complejidad, entre las que ingresan el Caos, el azar, la iterabilidad, los puntos convergentes aleatoriamente. No fue un cómplice de "los funcionarios" que desarrollan "los programas" pero, tampoco, de los "falsos" críticos que son incapaces de comprender las mutaciones que la digitalización produce. Su filosofía es creadora, intrigante, por momentos, confusa, ambigua y contradictoria. Se construye nómadicamente, trazando trayectos, dibujando mapas y cartografiando los territorios. Es una filosofía de la extranjería, de las “migraciones" conceptuales. Ya desde Língua e realidade, elogia el fenómeno de la migración. "Ser estrangeiro, portanto, é necessário, tanto quanto viajar, ou imigrar" (Bernardo, 2004, p. 11).

Así, el "fantasma" de Flusser se nos aparece y (des)aparece entre máquinas, espectros y fantasmagorías. Entre lenguas, territorios y culturas. La "magia” cruza por su cuerpo y des-codifica la linealidad de la historia y de la escritura que ésta produjo consiguientemente. Constituye una poderosa máquina conceptual y una clave fundamental para pensar los desafíos postmetafísicos de la era de las miradas desprendidas de las imágenes. 


\section{Bibliografia}

BERNARDO, G. "Préfacio”. In: FLUSSER, V. Língua e realidade. São

Paulo, Annablume, 2004.

DERRIDA, J. De la gramatología. México: Siglo XXI, 1971.

EAGLETON, T. La estética como ideología. Madrid: Trotta, 2006.

FLUSSER, V. Los gestos: fenomenología y comunicación. Barcelona:

Herder, 1994.

. Una filosofía de la fotografía. Madrid: Síntesis, 2001.

Filosofía del diseño. Madrid: Síntesis, 2001.

. Da religiosidade: a literatura e o senso da realidade. São

Paulo: Escrituras, 2002(b).

"La apariencia digital". In: YOEL, G. Pensar el cine 2.

Buenos Aires: Manantial, 2004.

"La sociedad alfanumérica". In: Revista Austral de Ciências

Sociales, n. 9, 2005.

. O mundo codificado. São Paulo: Cosac Naify, 2007.

. O universo das imagens técnicas: elogio da superficialidade.

São Paulo: Annablume, 2008.

GULDIN, R. "Derrida e Flusser: no conceito da escrita e o fim da linearidade". In: Ghrebh: revista de comunicação, cultura e teoria da mídia. São Paulo, v. 1, n. 11, 2008. Disponível em: $<$ www.dubitoergosum.xpg.com.br/az10.htm>.

SODRÉ, M. Reinventando la cultura. Barcelona: Gedisa, 1996. 